\title{
Genetic segregation analysis of familial mitral valve prolapse shows no linkage to fibrillar collagen genes
}

\author{
PAUL WORDSWORTH, * DONALD OGILVIE, * FAWAZ AKHRAS, $\dagger$ \\ GRAHAM JACKSON, $\dagger$ BRYAN SYKES * \\ From the ¿niversity of Oxford, Nuffield Department of Pathology, John Radcliffe Hospital, Oxford, and \\ $\dagger$ †ing's College Hospital, Department of Cardiology, London
}

SUMMARY Three pedigrees were identified in which mitral valve prolapse seemed to be inherited? as a mendelian autosomal dominant trait. The segregation of the genes encoding the major fibrillar ${ }_{\dot{\omega}}^{\omega}$ collagens present in valve tissue, collagens I and III, was analysed by use of restriction enzyme site $\odot$ variants as genetic markers. In one pedigree there was discordance between the segregation of the을 disease and markers for all three collagen genes. In another, there was discordance between thedisease and markers for both collagen I loci. This is evidence against the disease being generally the 3 result of mutations of the genes encoding the major fibrillar collagens.

Mitral valve prolapse is one of the commonest human cardiac abnormalities, with a prevalence of about $5 \%$. However, it has also been recognised, through improvements in echocardiography, that there is considerable variation in mitral valve mobility in the healthy population. Nevertheless, mitral valve prolapse can be identified as a distinct entity by applying strict diagnostic criteria relating to the degree of redundancy of the valve and the presence of mitral regurgitation. Most affected individuals are symptom free but a proportion suffer from atypical chest pain. Infective endocarditis, spontaneous cordal rupture, progressive mitral regurgitation, and sudden death are rare complications. The earliest histological change in mitral valve prolapse is disruption of the pars fibrosa with fragmentation of collagen bundles and an associated myxomatous degeneration. Subsequent changes include thickening of the endocardial surfaces and dilatation of the mitral annulus, both consequences of the stretching and elongation process initiated by the primary structural degeneration. The subject has been well reviewed..$^{1-7}$

Two arguments have persuaded investigators that the primary change that initiates the pathological sequence might be a collagen abnormality. Firstly, collagen is the major stress bearing component of the pars fibrosa. Secondly, mitral valve prolapse is a complication of some inherited connective tissue disorders in which there is evidence of a systemic

Requests for reprints to Dr Bryan Sykes, Nuffield Department of Pathology, John Radcliffe Hospital, Oxford OX3 9DU.

Accepted for publication 8 December 1988 collagen abnormality. These include the Marfan $\infty$ syndrome, ${ }^{89}$ Ehlers-Danlos syndrome, ${ }^{10}$ and osteogenesis imperfecta ${ }^{11}$ though whether the prevalence of mitral valve prolapse is any higher in osteogenesis imperfecta than in the normal population has recently been questioned.12 Mitral valve prolapse has also been associated with less well $\stackrel{\complement}{\varrho}$ defined connective tissue disorders such as the joint $\vec{\overrightarrow{ }}$ hypermobility syndrome. ${ }^{13}$

Primary mitral valve prolapse, uncomplicated by other symptoms of connective tissue disease, can appear as an inherited trait. The familial nature was first detected by the finding of systolic clicks and murmurs in two or three generations of several pedigrees. ${ }^{14}{ }^{15}$ As echocardiography improved the 3 diagnostic sensitivity, the number of affected first 8 degree relatives rose towards $50 \%$-the value expected for an autosomal dominant trait with full pen- 0 etrance. ${ }^{16-18}$ When, in some series, lower values were reported, ${ }^{19}$ this was attributed to technical differen- $\frac{T}{0}$ ces in recognition or reduced penetrance. There was complete concordance in six pairs of monozygotic $\sigma$ twins. ${ }^{15021}$ Most series have noted that the expres- N sion is affected by sex; the incidence among male first N degree relatives is about half that in females. There ${ }_{\sigma}$ also seems to be an age dependent expression with a significant increase in adults compared with children. The net result of these studies is the recognition of primary mitral valve prolapse as an autosomal dominant trait with incomplete penetrance and 0 variable expression.

As is often the case, precise defects in collagen have $\frac{\mathcal{D}}{\mathscr{Q}}$ been difficult to pinpoint. The loose arrangement of 
collagen bundles seen in the pars fibrosa with broken and coiled fibres undoubtedly has mechanical consequences for the leaflets. Analytical studies have shown a higher rate of collagen synthesis in cultured affected valves than in controls but they did not identify a specific cause. ${ }^{22}$

The predominant collagens in the mitral valve are collagens I and III, though there are also appreciable amounts of collagen $\mathrm{V} .{ }^{23}$ Fibrillar collagens are triple helical trimers that form stress resisting fibres via a system of intermolecular covalent bonds. Collagen I, the major species in the valve and chordae, has two distinct subunits, called the alpha-1 and alpha-2 chains, each molecule being a heterotrimer of two alpha-1 and an alpha-2 chain. Collagen III, on the other hand, is a homotrimer of three identical chains. The collagen I subunits are encoded at the COL1A1 (alpha-1 chains) and COL1A2 (alpha-2 chains) structural genes that in human beings have been localised to the non-syntenic loci on $17 q$ and $7 q$ respectively. The collagen III subunit is encoded at COL $3 A 1$ on 2q.

For the following reasons we set out to analyse the segregation of these three loci in pedigrees of dominantly inherited mitral valve prolapse. Firstly, if the primary defect in primary mitral valve prolapse is indeed a collagen defect then one possibility is that it is caused by a mutation in one of the structural genes. Mutations in these genes are known to cause some, but not all, of the inherited connective tissue disorders with which mitral valve prolapse can be associated. Secondly, although several other genes direct collagen synthesis, notably those encoding the eight enzymes that modify the protein after translation, the dominant inheritance of mitral valve prolapse suggests that the defect is likely to be in a structural protein rather than an enzyme. Enzyme deficiencies are usually inherited as recessive traits. Thirdly, segregation analysis is a rigorous method for testing candidate genes where, as in the collagen genes, very close markers are available, because any examples of discordance between the candidate gene and the disease gene in a pedigree immediately excludes it as the mutant locus.

\section{Patients and methods}

Three pedigrees were ascertained through proposita attending cardiac clinics in London and Oxford.

\section{ASSIGNMENT OF PHENOTYPE}

Patients and their relatives were examined clinically and by auscultation (table 1). We took special care to examine for signs of mild systemic connective tissue disease such as joint laxity, skin hyperextensibility, increased span/height ratios, and unusual scleral hue. None was found. Mitral valve prolapse was detected or confirmed by both $\mathbf{M}$ mode and cross sectional echocardiography by a Hewlett Packard phased array ultrasound system with $3.5 \mathrm{MHz}$ transducer. M mode echocardiography was recorded with the transducer placed perpendicular to the chest wall. The beam was aimed towards the atrioventricular groove or proximal free wall of the left atrium from the parasternal window while both leaflets of the mitral valve were imaged simultaneously. Cross sectional

Table 1 Phenotype of affected family members

\begin{tabular}{|c|c|c|c|c|c|c|c|}
\hline \multirow[b]{2}{*}{ Pedigree } & \multicolumn{4}{|c|}{ Clinical } & \multicolumn{2}{|c|}{ Auscultation } & \multirow[b]{2}{*}{ Other } \\
\hline & Age & Palpitation & Dyspnoea & $\begin{array}{l}\text { Atypical } \\
\text { chest pain }\end{array}$ & $\begin{array}{l}\text { Systolic } \\
\text { click }\end{array}$ & $\begin{array}{l}\text { Systolic } \\
\text { murmur }\end{array}$ & \\
\hline $\begin{array}{l}\text { Pedigree 1: } \\
\text { I.2 } \\
\text { III.2 } \\
\text { II.4 }\end{array}$ & $\begin{array}{l}65 \\
39 \\
38\end{array}$ & $\begin{array}{l}1 \\
1 \\
1\end{array}$ & $\begin{array}{l}1 \\
1 \\
0\end{array}$ & $\begin{array}{l}0 \\
1 \\
0\end{array}$ & $\begin{array}{l}1 \\
0 \\
1\end{array}$ & $\begin{array}{l}1 \\
2 \\
1\end{array}$ & Mitral valve replaced \\
\hline $\begin{array}{l}\text { Pedigree 2: } \\
\text { II.5 } \\
\text { III.2 } \\
\text { III.3 } \\
\text { III.5 } \\
\text { III.6 }\end{array}$ & $\begin{array}{l}48 \\
27 \\
26 \\
18 \\
16\end{array}$ & $\begin{array}{l}1 \\
0 \\
0 \\
1 \\
0\end{array}$ & $\begin{array}{l}0 \\
0 \\
0 \\
0 \\
0\end{array}$ & $\begin{array}{l}0 \\
0 \\
0 \\
1 \\
0\end{array}$ & $\begin{array}{l}2 \\
0 \\
1 \\
1 \\
2\end{array}$ & $\begin{array}{l}0 \\
1 \\
1 \\
1 \\
0\end{array}$ & \\
\hline $\begin{array}{l}\text { Pedigree 3: } \\
\text { II.1 } \\
\text { II.5 } \\
\text { III.2 } \\
\text { III.3 } \\
\text { III.5 } \\
\text { III.7 } \\
\text { III.8 } \\
\text { IV.2 }\end{array}$ & $\begin{array}{r}53 \\
44 \\
29 \\
27 \\
20 \\
16 \\
12 \\
4\end{array}$ & $\begin{array}{l}1 \\
0 \\
0 \\
0 \\
0 \\
0 \\
0 \\
0\end{array}$ & $\begin{array}{l}1 \\
0 \\
0 \\
0 \\
0 \\
0 \\
0 \\
0\end{array}$ & $\begin{array}{l}1 \\
0 \\
1 \\
0 \\
0 \\
0 \\
0 \\
0\end{array}$ & $\begin{array}{l}1 \\
1 \\
1 \\
1 \\
2 \\
1 \\
2 \\
1\end{array}$ & $\begin{array}{l}0 \\
0 \\
1 \\
0 \\
0 \\
0 \\
0 \\
0\end{array}$ & \\
\hline
\end{tabular}

$0=$ feature absent; 1 = feature present except for systolic click where $1=$ single click, $2=$ double click, and systolic murmur where $1=$ late systolic, 2 = pansystolic. Mitral valve prolapse was confirmed by echocardiography in all family members scored as affected. 


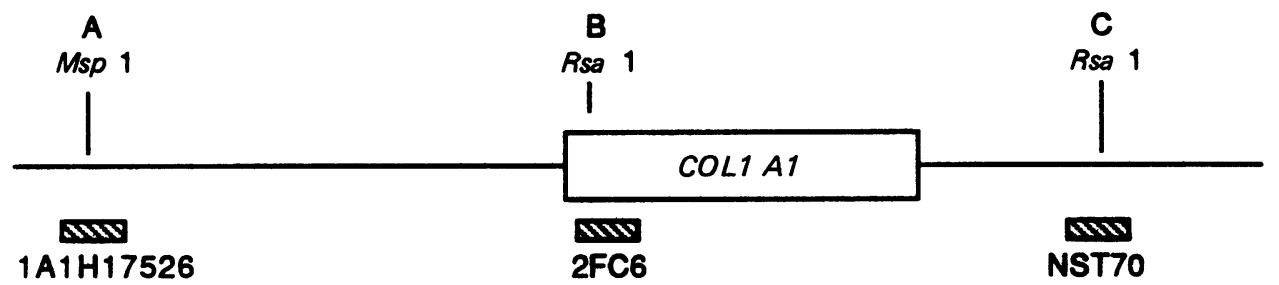

$\begin{array}{lll}1 \text { A1H17526 } & \text { 2FC6 } & \text { NST70 }\end{array}$

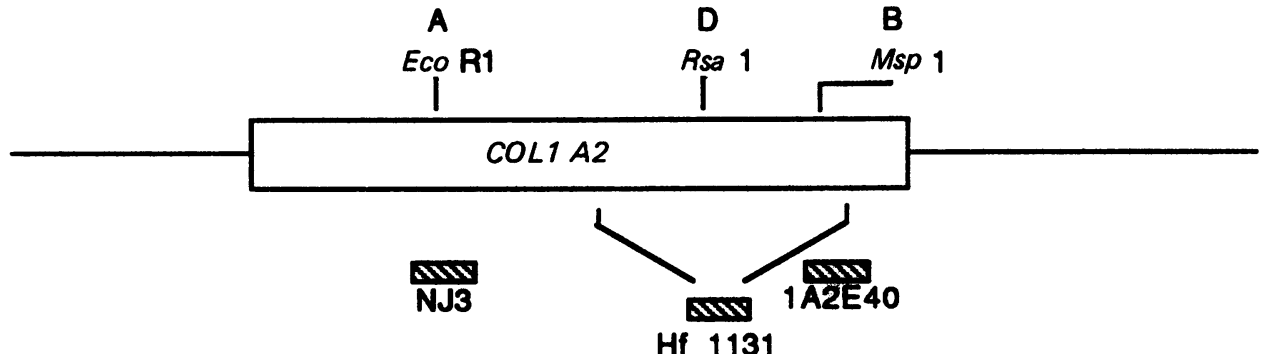

Hf 1131
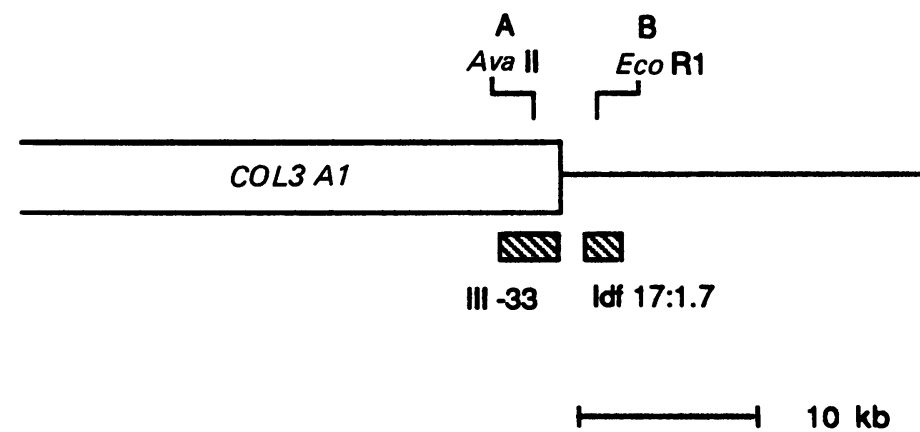

Fig 1 Map of the segregation marker systems at COL1A1,COL1A2, and COL3A1.

echocardiography recordings were made from the parasternal long axis and the apical four chamber views.

\section{Pedigree 1}

Propositus II.2-A 39 year old man with a known family history of mitral valve prolapse underwent emergency mitral valve replacement because of worsening congestive heart failure in the presence of a recent pansystolic murmur. Although he had had a heart murmur since birth he had been symptom free until a few years ago when he first experienced recurrent episodes of palpitation and mild chest pain unrelated to exercise. He made a good recovery.

\section{Pedigree 2}

Propositus III.5-A 19 year old man presented with a history of recurrent episodes of palpitation. The physical examination was entirely normal except for a late systolic click followed by a murmur heard over the mitral area. Echocardiographic examination showed considerable elongation of the anterior mitral valve leaflet and a mobile cystic mass that seemed to be continuous with its tip. The findings in this case have been described elsewhere. ${ }^{24}$

\section{Pedigree 3}

Propositus III.2-A 29 year old man presented with a history of atypical chest pain and palpitation. $\delta$ A late systolic click and murmur were heard over the $₹$ apex. The physical examination was otherwiseo unremarkable. The echocardiographic examination showed similar appearances to those seen in pedigree 2.

Table 1 summarises the clinical, auscultatory, and $\%$ echocardiographic findings in the affected family $N^{\circ}$ members. Relatives scored as unaffected were normal $N_{\mathcal{W}}$ for all variables tested.

\section{ASSIGNMENT OF GENOTYPE}

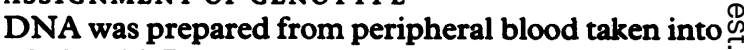
edetic acid. Restriction enzyme digestion and agarose 0 electrophoresis blotting on to nitrocellulose filters ${ }_{0}^{\circ}$ followed our modifications of standard protocols. ${ }^{25} \stackrel{\mathrm{D}}{\mathrm{O}}$ Hybridisation probes (fig 1 ) were labelled with ${ }^{32} \mathrm{P}$ by $\mathbb{D}$ either nick translation or random primer directed 
Table 2 Haplotype notations at COL1A1, COL1A2, and COL3A1

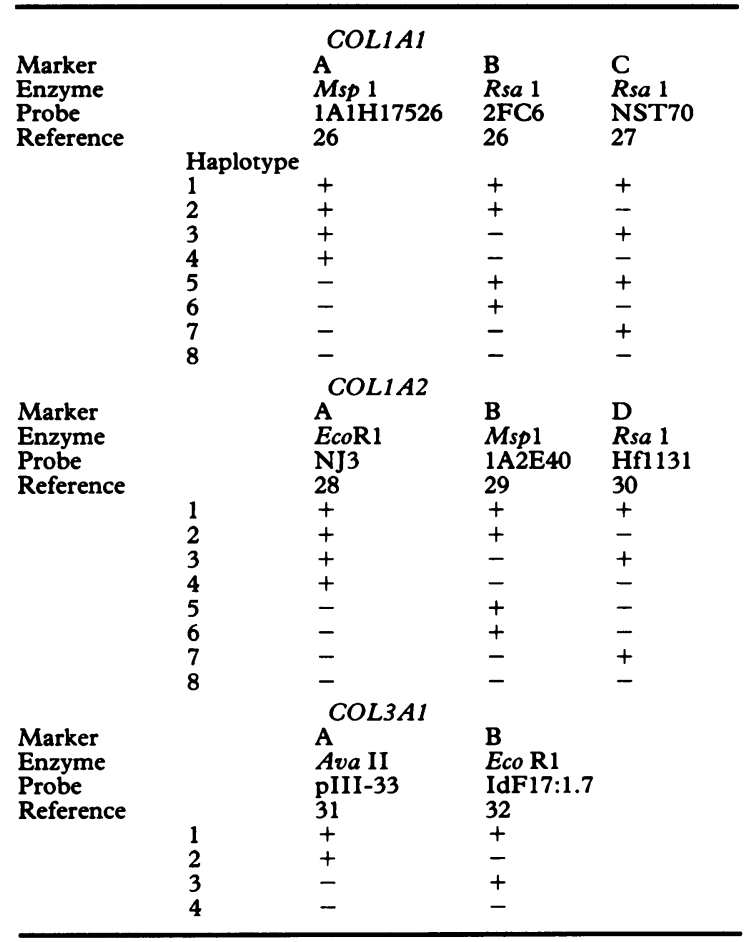

synthesis. Hybridisations were carried out overnight at $42^{\circ} \mathrm{C}$ in a mixture containing $50 \% \mathrm{v} / \mathrm{v}$ formamide, $5 \% \mathrm{w} / \mathrm{v}$ dextran sulphate, and $200 \mu \mathrm{g} / \mathrm{ml}$ heparin after prehybridisation of the filter overnight with the same mixture without dextran sulphate.

Three restriction site dimorphisms at both COL1A1, ${ }^{2627} \mathrm{COL1A2} 2^{28-30}$ and two at COL $3 \mathrm{Al}^{3132}$ were used as genetic linkage markers. Figure 1 shows the positions of the markers on the physical gene maps. Use of these three markers distinguished eight haplotypes at both COL1A1 and COL1A2 with four possible combinations allowed at COL $3 A 1$. Table 2 shows the notations of markers at the three loci. Where it was relevant to the analysis we confirmed paternity or maternity by means of the minisatellite probe 15.1.11.4. ${ }^{33}$

\section{Results}

Figure 2 shows the genotypes at the three loci and table 3 summarises the results. Discordance between markers and mitral valve prolapse was seen in the pedigrees as follows.

\section{Pedigree 1}

COL1A2-Both II.2 and II.4 have inherited the gene for mitral valve prolapse from their mother I.2 but different COL1A2 alleles.

$C O L 1 A 1$ and $C O L 3 A 1$ markers at both loci were both non-informative because I.2 was homozygous in each case so the alleles could not be distinguished.

\section{Pedigree 2}

COL1 A1-III. 2 and III. 3 both inherited the gene for mitral valve prolapse from their mother II.5 but different COL $1 A 1$ alleles.

COL1A2-Both II.4 and III.2 are double heterozygotes for COL1A2 markers. This means that they could have one of two possible genotypes 14 or 2-3 though examination of the pedigree shows that both individuals must have the same genotype. Consider the case where II.4 and III.2 have genotype 1-4 at COL1A2. In this case, III.2 must have inherited allele 4 from her father and allele 1 from her mother. However, III.3 must have inherited allele 1 from her father and allele 2 from her mother. So the two daughters have received different COL1A2 alleles from their mother but both have inherited the gene for mitral valve prolapse. Much the same argument applies if both II.4 and III.2 have genotypes 2-3. In this case II.5 has passed allele 2 to her daughter III.2 and allele 1 to III. 3 but the gene for mitral valve prolapse to both.

COL3A1-II.5 is homozygous for COL3A1 markers so the pedigree is not informative.

Individual II.1, who was not examined, was reported to have been turned down for army selection because of a heart murmur. This raises the possibility that the gene for mitral valve prolapse is present in his sibs, one of whom is II.4, the father of the affected individuals in generation III. II.4 was thoroughly examined and no signs of mitral valve prolapse were seen by careful auscultation or echocardiography.

\section{Pedigree 3}

COL1A1-III.5 carries the gene for mitral valve prolapse but has no COL1A1 allele in common with either his two brothers III.2 and III.3 or his niece IV.2, all of whom also carry the gene for mitral valve prolapse.

COL1A2-III.2 and III.3 are both affected but have no COL1A2 alleles in common.

COL $3 A 1$-Consider III.7 and III.8. Both are affected but have inherited different COL $3 A 1$ alleles from their father.

\section{Discussion}

Several factors complicate linkage analysis in disorders such as mitral valve prolapse. First, it is a 


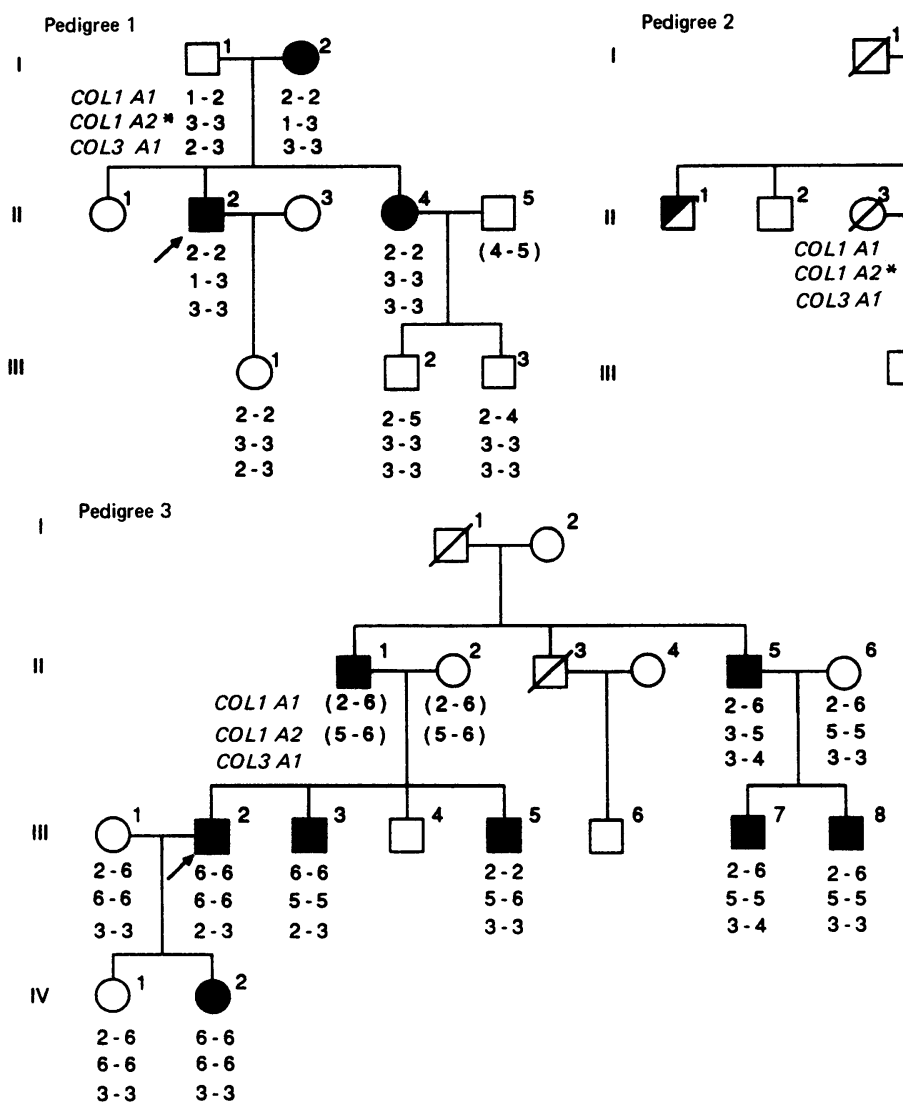

Fig 2 Three pedigrees showing mitral valve prolapse with collagen genotypes are shown in table 1. Black symbols are individuals scored as affected, white symbols are individuals who did not show symptoms of mitral valve prolapse. Propositi are arrowed. The partly shaded symbol indicates an individual II.1 in pedigree 2 who was not examined but was turned down by the army because of $a$ "heart murmur". In pedigrees 2 and 3, the COL1 A2` haplotypes are incomplete and are as follows: $1=A+B+; 2=A+B-; 3=A-B+; 4=A-B-$. Deduced genotypes are shown in parentheses.

common disorder so that sibships may receive mitral valve prolapse genes from both parents. Second, the penetrance is incomplete. This makes analysis based on unaffected individuals more uncertain than in fully penetrant disorders because there is a high probability that they may have inherited the gene

Table 3 Segregation of COL1A1, COL1A2, and COL3A1 in three pedigrees showing mitral valve prolapse

\begin{tabular}{llll}
\hline & \multicolumn{2}{l}{ Locus } & \\
\cline { 2 - 4 } Pedigree & COL1A1 & COL1A2 & COL3A1 \\
\hline & $N I$ & $D S$ & $N I$ \\
& $D S$ & $D S$ & $D S$ \\
& $D S$ & $D S$ & $D S$ \\
\hline
\end{tabular}

NI, non-informative; DS, discordant. without its expression being detected in the phenotype despite very careful examination. Third, it is not clear that mitral valve prolapse is always inherited so that there is a possibility that individuals in apedigree scored as affected may not have received the mutant gene but are phenocopies for an unrelated reason.

Bearing these important considerations in mind we, showed that neither of the two genes encoding the subunits of collagen I segregated with the mitral ${ }^{\omega}$ valve prolapse phenotype in two pedigrees in which 2 the disorder appeared to be behaving as an autosomafo dominant mendelian trait. In a third pedigree we excluded one of the genes, COL1A2, but not the other. Largely because of a lack of useful markers at COL3A1, we have only been able to analyse the segregation of this locus in one pedigree and this analysis showed discordance. 
There are several reasons why we are cautious about interpretation of these results, but we can discount the probability of recombination between the markers at the loci and the physical limits of the gene. The maximum distance between markers is $50 \mathrm{~kb}$ which, barring unusually high recombination rates at the loci, translates to a crossover frequency of about 0.0005 per meiosis. This is insignificant compared with the other potential sources of error.

This study can only be regarded as preliminary and needs to be extended to larger pedigrees in which the segregation of the disease as an autosomal dominant trait is clearer and discordance can be demonstrated in several meioses. Nevertheless, this study suggests that the primary gene locus for mitral value prolapse is not linked to either of the two collagen I loci nor, probably, to the collagen III locus. If this is the case then mutations in these genes cannot be the cause of the disease.

We thank the patients and their physicians whe took part in this study especially $\mathrm{Dr} \mathrm{J}$ Walker for echocardiography of pedigree 1 . We are grateful to Dr F Ramirez for COL1A2 probes NJ3 and Hf1131, to Dr R Dalgleish for COL $3 A 1$ probes pIII-33 and IdF 17:1.7, and to Dr A Jeffreys for minisatellite probe 15.1.11.4. We thank the Arthritis and Rheumatism Council, Action Research for the Crippled Child, and the Medical Research Council for support.

\section{References}

1 Wynne J. Mitral valve prolapse. $N$ Engl J Med 1984;314:577-8.

2 Oakley CM. Mitral valve prolapse; harbinger of death or variant of normal. Br Med J 1984;288:1853-4.

3 Devereux RB, Brown WE. Genetics of mitral valve prolapse. Prog Med Genet 1983;5:139-61.

4 Procacci PM, Savran SV, Schreiter SL, Bryson AL. Prevalence of clinical mitral valve prolapse in 1169 young women. $N$ Engl J Med 1976;294:1086-8.

5 Malcolm AD, Boughner DR, Kostuk WJ, Ahuja SP. Clinical features and investigative findings in presence of mitral leaflet prolapse: study of 85 consecutive patients. Br Heart J 1976;38:244-56.

6 Davies MJ, Moore BP, Braimbridge MV. The floppy mitral v'ilve: study of incidence, pathology, and complications in surgical, necropsy, and forensic material. Br Heart J 1978;40:468-81.

7 Sbarbaro JA, Mehlman DJ, Wu L, Brooks HL. A prospective study of mitral valvular prolapse in young men. Chest 1079;75:555-9.

8 Pyertiz RE, McJusick VA. The Marfan syndrome: diagnosis and management. $N$ Engl $J$ Med 1979;30:772-7.

9 Brown OR, DeMots H, Kloster FE, Roberts A, Menashe VD, Beals RK. Aortic root dilatation and mitral valve prolapse in Marfan's syndrome. Circula- tion 1975;52:651-7.

10 Cabeen WR Jr, Reza MJ, Kovick RB, Stern MS. Mitral valve prolapse and conduction defects in Ehlers-Danlos syndrome. Arch Intern Med 1977; 137:1227-31.

11 Wood SJ, Thomas J, Braimbridge MV. Mitral valve disease and open heart surgery in osteogenesis imperfecta tarda. Br Heart J 1973;35:103-6.

12 Hortop J, Tsipouras P, Hanley JA, Maron BJ, Shapiro MR. Cardiovascular involvement in osteogenesis imperfecta. Circulation 1986;73:54-61.

13 Grahame R, Edwards JC, Pitcher D, Gabell A, Harvey WA. A clinical and echocardiographic study of patients with the hypermobility syndrome. Ann Rheum Dis 1981;40:541-6.

14 Hancock EW, Cohn $\mathrm{K}$. The syndrome associated with midsystolic click and late systolic murmur. Am J Med 1966;41:183-96.

15 Rizzon P, Biasco G, Brindicci G, Mauro F. Familial syndrome of midsystolic click and late systolic murmur. Br Heart J 1973;35:245-59.

16 Weiss AN, Mimbs JW, Ludbrook PA, Sobel BE. Echocardiographic detection of mitral valve prolapse. Exclusion of false positive diagnosis and determination of inheritance. Circulation 1975;52:1091-6.

17 Fortuin NJ, Strahan NY, Come PC, Hymphries JO, Murphy EA. Inheritance of the mitral valve prolapse syndrome [Abstract]. Clin Res 1977;25:470A.

18 Devereux RB, Brown WT, Kramer-Fox R, Sachs I. Inheritance of mitral valve prolapse: effect of age and sex on gene expression. Ann Intern Med 1982;97: 826-32.

19 Takeda P, Bommer W, Kuran OL, et al. How frequent is familial transmission of mitral valve prolapse. Evaluation by two-dimensional echocardiography and phonocardiogram [Abstract]. Circulation 1980; (Suppl III):206.

20 Girard DE, Girard JB. Mitral valve prolapse-click syndrome in twins. Am Heart J 1977;94:813-5.

21 Jerasty RM. Mitral valve prolapse. New York: Raven Press, 1979.

22 Henney AM, Parker DJ, Davies MJ. Collagen biosynthesis in normal and abnormal human heart valves. Cardiovasc Res 1982;16:624-30.

23 Cole WG, Chan D, Hickey AJ, Wilcken DE. Collagen composition of normal and myomatous human mitral valves. Biochem J 1984;214:451-60.

24 Akhras F, Jackson G. Familial cystic malformation of the mitral valve: echocardiographic appearances [Abstract]. Proceedings of the 6th Symposium on Echocardiography, 1985:87.

25 Sykes BC, Ogilvie DJ, Wordsworth BP. Lethal osteogenesis imperfecta and a collagen gene deletion. Length polymorphism provides an alternative explanation. Hum Genet 1985;70:35-7.

26 Sykes BC, Ogilvie DJ, Wordsworth BP, Anderson J, Jones $\mathbf{N}$. Osteogenesis imperfecta is linked to both Type I collagen structural genes. Lancet 1986;i: 69-72.

27 Ogilvie DJ, Aitchison KJ, Sykes BC. An RFLP close to the human collagen I gene COL1A1. Nucleic Acids Res 1987;15:4699.

28 Tsipouras P, Myers JC, Ramirez F, Prockop DJ. 
Restriction fragment length polymorphism associated with the pro-alpha-2(I) gene of human type I procollagen. J Clin Invest 1983;72:1262-7.

29 Grobler-Rabie AF, Brebner DK, Vandenplas S et al. Polymorphism of DNA sequence in the pro- $\alpha 2(\mathrm{I})$ collagen gene. J Med Genet 1985;22:182-6.

30 Grobler-Rabie AF, Wallis G, Brebner DK, Beighton P, Bester AF, Mathew CGP. Detection of a highfrequency Rsa 1 polymorphism in the human pro$\alpha 2(\mathrm{I})$ collagen gene which is linked to an autosomal dominant form of osterogenesis imperfecta. EMBO J

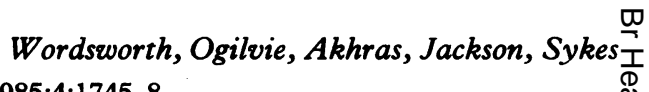
1985;4:1745-8.

31 Dalgleish $R$, Woodhouse $M$, Reeders S. An RFLP associated with human Type III collagen gene (COL3A1). Nucleic Acids Res 1985;13:4609.

32 Tsipouras P, Byers PH, Schwartz RC, et al. Ehlers Danlos syndrome type IV: cosegregation of the phenotype to a COL3A1 allele of type III procollagen. Hum Genet 1986;74:41-6.

33 Jeffreys AJ, Wilson V, Thein SL. Hypervariabl $\$$ "minisatellite" regions in human DNA. Nature 19859 314:67-73. 